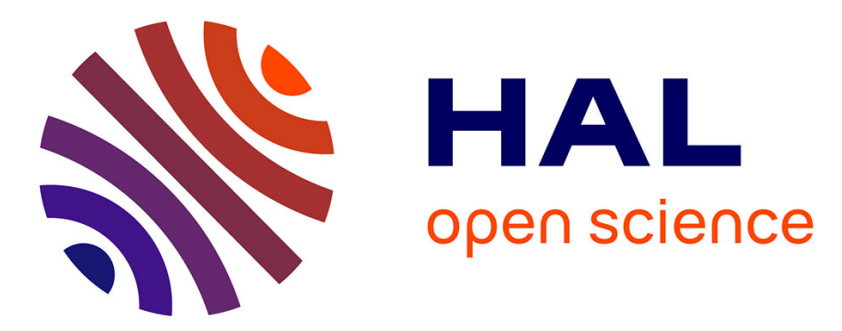

\title{
Scenario analysis for cereal management in water-limited conditions by the means of a crop simulation model (STICS)
}

Philippe Debaeke

\section{- To cite this version:}

Philippe Debaeke. Scenario analysis for cereal management in water-limited conditions by the means of a crop simulation model (STICS). Agronomie, 2004, 24 (6-7), pp.315-326. 10.1051/agro:2004035 . hal-00886037

\section{HAL Id: hal-00886037 https://hal.science/hal-00886037}

Submitted on 1 Jan 2004

HAL is a multi-disciplinary open access archive for the deposit and dissemination of scientific research documents, whether they are published or not. The documents may come from teaching and research institutions in France or abroad, or from public or private research centers.
L'archive ouverte pluridisciplinaire HAL, est destinée au dépôt et à la diffusion de documents scientifiques de niveau recherche, publiés ou non, émanant des établissements d'enseignement et de recherche français ou étrangers, des laboratoires publics ou privés. 


\title{
Scenario analysis for cereal management in water-limited conditions by the means of a crop simulation model (STICS)
}

\author{
Philippe DEBAEKE* \\ UMR 1248 INRA-ENSAT « Agrosystèmes Cultivés et Herbagers » (ARCHE), BP 27, 31326 Castanet-Tolosan Cedex, France
}

(Received 16 July 2003; accepted 8 January 2004)

\begin{abstract}
Crop simulation models are frequently used to evaluate the impacts of water resources (soil, weather and irrigation) on crop production and the environment. This study illustrates the possibilities offered by STICS 4.0 in water-limited environments. Numerical experiments were carried out on winter wheat in order to evaluate drought escape and crop rationing in 3 climatic environments: Avignon, Meknès (Morocco) and Toulouse. The Passioura [33] framework which disaggregates grain yield of cereals into 3 terms: water transpired, transpiration efficiency and the harvest index, was used to analyze the simulation results. Interactions between cultivar earliness and water supply were shown for yield: early-maturing genotypes yielded more in semi-arid conditions because of terminal stress; where intermittent stress was observed (as in Toulouse), no stable ranking was observed between cultivars differing by the date of anthesis. The contribution of soil evaporation to total water use was reduced by rapid canopy closure (fast-growing cultivar and high plant density). On the other hand, water stress during grain filling was more frequent with excessive plant density. Crop management systems resulting from different combinations of cultivar earliness, plant density and supplemental irrigation were simulated: a drought-escaping strategy (early genotype) and crop rationing (low plant density) were suggested under rainfed (semi-arid) conditions. With irrigation or under wetter conditions, yield should be improved by maximizing early canopy closure (high density) and lengthening the growing season period (late genotype). This simulation exercise contributed to the qualitative evaluation of the STICS model for water-limited agriculture.
\end{abstract}

crop management / water-limited environment / scenario analysis / wheat / irrigation

\section{INTRODUCTION}

Two main strategies of crop adaptation to drought-stressed environments have been described in the literature [28]: (i) drought escape, whereby the crop completes its life before the onset of "terminal drought", and (ii) drought tolerance, where the crop continues to grow and function at reduced water contents. These concepts are generally used to discuss genotypic adaptation to water deficit [29]. Additional strategies are offered by crop management: (iii) drought alleviation or moderation, by the means of supplemental irrigation [21], and (iv) an optimal crop water-use pattern (or drought avoidance), by reducing soil evaporation and increasing the contribution of transpiration during the grain-filling period [35, 38]. The expression "vegetative rationing" was suggested to describe a strategy based on the early reduction of crop water uptake in order to save water for the most susceptible growth stages (anthesis and grain filling) [20]. In the areas and cropping systems where yield is chronically limited by water availability (shallow soils, low precipitation, high evaporative demand and limited irrigation), the farmer has to apply the best combination of genotypic and management strategies to reduce the impacts of water deficit while not affecting yield potential excessively during the wettest years [17, 18, 23].

Dynamic crop simulation models are relevant tools for evaluating cultural practices under water-limited conditions as traditional field trials cannot explore the full range of crop-soilweather- management interactions [37]. In the last 15 years, on the basis of ecophysiological studies, numerous soil-plant models (either crop-specific or generic) have been developed to simulate soil water dynamics and the response of major crops to water use: APSIM [30], CropSyst [40], EPIC-Phase [15] and STICS [11] being among the most recent ones. Using historical or computer-generated weather information as inputs, these mechanistic models, more or less complex, have been used extensively to determine the probability of yield response to various combinations of crop management, including the amount of soil water at sowing, sowing date, cultivar phenology, plant population and supplemental irrigation and to define at the field or farm level the optimal irrigation schedules or combinations of techniques in various water-limited environments $[1,3,14,16,17,19,23,31,32,34-36,39]$.

\footnotetext{
* Corresponding author: debaeke@toulouse.inra.fr
} 
Table I. Main climatic characteristics of the 3 locations used for scenario analysis; CV $=$ coefficient of variation.

\begin{tabular}{|c|c|c|c|c|c|c|c|c|}
\hline \multirow[b]{2}{*}{ Locations } & \multirow[b]{2}{*}{ Years } & \multirow{2}{*}{$\begin{array}{c}\mathrm{P} / \mathrm{ET}_{\text {ref }} \\
\text { Annual }\end{array}$} & \multicolumn{4}{|c|}{ Rainfall (mm) } & $\begin{array}{l}\text { Radiation } \\
\left(\mathrm{MJ} \cdot \mathrm{m}^{-2}\right)\end{array}$ & $\begin{array}{c}\text { Temperature } \\
\left({ }^{\circ} \mathrm{C}\right)\end{array}$ \\
\hline & & & Annual & $\begin{array}{l}\text { October-March } \\
\text { (winter) }\end{array}$ & $\begin{array}{c}\text { November-June } \\
\text { (wheat growing } \\
\text { season) }\end{array}$ & $\begin{array}{l}\text { May-June } \\
\text { (anthesis + } \\
\text { grain filling) }\end{array}$ & \multicolumn{2}{|c|}{$\begin{array}{c}\text { November-June } \\
\text { (wheat growing season) }\end{array}$} \\
\hline Meknès & $\begin{array}{c}\mathrm{n}=37 \\
1960-1996\end{array}$ & $\begin{array}{c}0.36 \\
(0.2-0.7)\end{array}$ & $\begin{array}{c}550 \\
\mathrm{CV}=30 \%\end{array}$ & 414 & 491 & 52 & 3636 & 14.2 \\
\hline Avignon & $\begin{array}{c}\mathrm{n}=33 \\
1969-2001\end{array}$ & $\begin{array}{c}0.69 \\
(0.3-1.1)\end{array}$ & $\begin{array}{c}697 \\
\mathrm{CV}=24 \%\end{array}$ & 365 & 430 & 103 & 3138 & 11.0 \\
\hline Toulouse & $\begin{array}{c}\mathrm{n}=31 \\
1971-2001\end{array}$ & $\begin{array}{c}0.81 \\
(0.4-1.3)\end{array}$ & $\begin{array}{c}707 \\
\mathrm{CV}=19 \%\end{array}$ & 339 & 498 & 145 & 2740 & 10.4 \\
\hline
\end{tabular}

The STICS model was described in 2 major papers [11, 13]. Like other models, STICS describes at a daily time-step the growth and development of a range of crops according to water and nitrogen availability. The model can integrate edaphic, climatic and crop management information to aid in identifying optimum cultural practices over time and space. The seven main modules are concerned with water availability: plant development, shoot growth, root growth, yield components, water balance, $\mathrm{N}$ balance, and soil and crop temperature. Water stress affects the leaf area index (LAI), shoot and root growth, assimilate partitioning (harvest index) and grain protein. The impact of water stress on crop phenology is simulated by using the crop temperature computed by means of a simplified energy balance, which is an original aspect of STICS. Manipulating LAI has a direct influence on soil and plant evaporation and on plant transpiration processes [10]. Soil moisture governs N transfer and transformations (e.g. humus mineralization). The STICS model was validated for wheat and maize in a range of climatic and cultural environments [12]. Soil water content was simulated accurately and wheat grain yield was represented with a error of $15 \%$. The model's robustness confirms its use for exploring wheat behavior in water-limited environments.

In the situations where water is the main limiting factor, Passioura [33] proposed that grain yield (GY) of cereals could be analyzed in terms of three factors that are largely independent:

GY $=$ Water transpired $(\mathrm{T}) \times$ Transpiration efficiency $(\mathrm{TE}) \times$ Harvest index (HI).

Transpiration (T) can be decomposed as follows (Es = soil evaporation):

$$
\mathrm{T}=(\mathrm{T}+\mathrm{Es}) /(1+\mathrm{Es} / \mathrm{T}) .
$$

Therefore increasing GY will be attained through increasing (1) total water use $(\mathrm{ET}=\mathrm{Es}+\mathrm{T})$, (2) plant transpiration relative to soil evaporation (T/Es), (3) transpiration efficiency ( $\mathrm{TE}=$ $\mathrm{DM} / \mathrm{T}, \mathrm{DM}$ for shoot biomass), and (4) the harvest index (HI = GY/DM). This generic framework is adequate for comparing different cereal management strategies. Each of the terms of equations (1) and (2) are output variables of the STICS model.

To increase total water use $(E s+T)$, two options are generally recommended: (i) maximizing the soil-stored water at planting (fallow management, choice of the previous crop, presowing irrigation, etc.) $[1,17,18]$, and (ii) filling the natural water deficit by supplemental irrigation at the most responsive periods in order to optimize the use of the other inputs (longseason cultivar, nitrogen and high crop density) [21]. A rapid canopy closure through high plant density, use of a genotype with high initial vigor and increased fertilization is a management goal that is often recommended to reduce the contribution of soil evaporation to total evapotranspiration (ET) [27, 38]. As transpiration efficiency is higher during periods of low vapor pressure deficit, as in the cool winter months, early sowings or the choice of early-growing cultivars which tolerate low temperatures generally result in higher values of TE [18]. The harvest index is increased when sufficient water is kept for the grain-filling period [33] which implies an adequate management of water losses during the vegetative period.

Using STICS 4.0 [9] and 30-yr historical weather information, a scenario analysis exercise was conducted to evaluate various strategies of crop management adaptation to water deficit such as soil water at sowing, plant density, cultivar maturity group and supplemental irrigation on wheat and sorghum yields over 30 growing seasons for three water-limited environments.

\section{MATERIALS AND METHODS}

\subsection{Weather data}

Historical weather records (> $30 \mathrm{yrs}$ ) were collected in 3 southern regions differing by total rainfall, its monthly distribution and the aridity index, which is the ratio of mean annual rainfall $(\mathrm{P})$ to mean annual reference evapotranspiration $\left(\mathrm{ET}_{\text {ref }}\right)$ (Tab. I) : (i) Meknès (Morocco) is a Mediterranean semi-arid (humid) climate with a $\mathrm{P} / \mathrm{ET}_{\text {ref }}$ ratio of 0.36 and $75 \%$ of annual rainfall concentrated in winter; (ii) Avignon (SE France) is Mediterranean sub-humid ( $\left.\mathrm{P} / \mathrm{ET}_{\mathrm{ref}}=0.69\right)$; (iii) Toulouse ( $\mathrm{SW}$ France) is sub-humid to humid ( $\mathrm{P} / \mathrm{ET}_{\text {ref }}=0.81$ ) exposed to oceanic influences. Solar radiation, air temperature and evapotranspiration are the highest in Meknès.

\subsection{Soil data}

We assumed a moderately deep soil $(1.2 \mathrm{~m})$ with available soil water (ASW) of $165 \mathrm{~mm}$ (i.e $1.4 \mathrm{~mm} / \mathrm{cm}$ ). The value of Qo 
Table II. Thermal duration of the development phases of STICS for 3 synthetic wheat cultivars differing only by development characteristics: sum of crop temperature expressed in degree days (base $0{ }^{\circ} \mathrm{C}$ ).

\begin{tabular}{|c|c|c|c|}
\hline \multirow[b]{2}{*}{ Phases } & \multicolumn{3}{|c|}{ Maturity group } \\
\hline & Early (E) & Medium (M) & Late (L) \\
\hline$\overline{\text { LEV-AMF }}$ & 275 & 237 & 200 \\
\hline AMF-LAX & 270 & 294 & 420 \\
\hline LAX-DRP & 105 & 175 & 230 \\
\hline DRP-MAT & 760 & 760 & 760 \\
\hline LEV-MAT & 1410 & 1466 & 1610 \\
\hline
\end{tabular}

LEV: emergence; AMF: end of juvenile phase (beginning of stem elongation for wheat);

LAX: maximum leaf area index (booting for wheat); DRP: beginning of grain filling (anthesis for wheat);

MAT: physiological maturity.

was fixed at 0 within the range of experimental values $(0-22 \mathrm{~mm})$ determined by Brisson and Perrier [8]. With such an assumption, soil evaporation was always limited by climatic and soil factors. At crop sowing, the soil was refilled at 50\% of ASW in standard conditions but 4 additional rates were tested at wheat and sorghum sowing: 10, 25, 75 and 100\% (field capacity). The initial mineral nitrogen content was $50 \mathrm{~kg} / \mathrm{ha}$ and the organic $\mathrm{N}$ content was $0.12 \%$.

\subsection{Crop management}

Winter wheat was sown on 15 November and two fixed applications of $\mathrm{N}$ fertilizer were carried out on 1st February $(50 \mathrm{~kg} / \mathrm{ha})$ and $15 \mathrm{March}(100 \mathrm{~kg} / \mathrm{ha})$. Wheat was kept rainfed or sprinkler irrigation was brought to the wheat using fixed amounts of $40 \mathrm{~mm} / \mathrm{ha}$ applied as soon as the turgor stress index (turfac) fell below 0.70 (automatic irrigation procedure). Standard plant density (d2) was 250 plants $/ \mathrm{m}^{2}$ and extremes of $150(\mathrm{~d} 1)$ and $450(\mathrm{~d} 3)$ plants per $\mathrm{m}^{2}$ were evaluated.

Rainfed grain sorghum was planted on 20 March at a density of 30 plants $/ \mathrm{m}^{2}$ and received $110 \mathrm{~kg} / \mathrm{ha}$ of nitrogen at sowing time.

\subsection{Cultivars}

The range of earliness (time to anthesis) commonly used in France (E, M and L) for bread wheat [25] was evaluated under the 3 climatic series. The thermal durations of the vegetative phases were expressed in crop temperature which is about $12 \%$ more than air temperature [11]. By activating the crop temperature option, wheat maturity was accelerated by water stress as commonly observed. The parameters characterizing crop development are presented in Table II for the 3 synthetic wheat cultivars.

Under rainfed conditions, physiological maturity occurred on 24 June (Toulouse), 17 June (Avignon) and 2 June (Meknès) on average. The length of the sowing-maturity period ranged from 202 to 238 days under rainfed conditions: in Toulouse, the growing season lasted 7 days more than in Avignon and 21 days more than in Meknès. The length of the emergence-anthesis period (LEV-DRP) ranged from 147 (25 April) to 185 days (2 June) according to location and cultivar earliness (Fig. 1a). In Meknès, irrigation resulted in a lengthening and a reduction of the variability of the period duration.
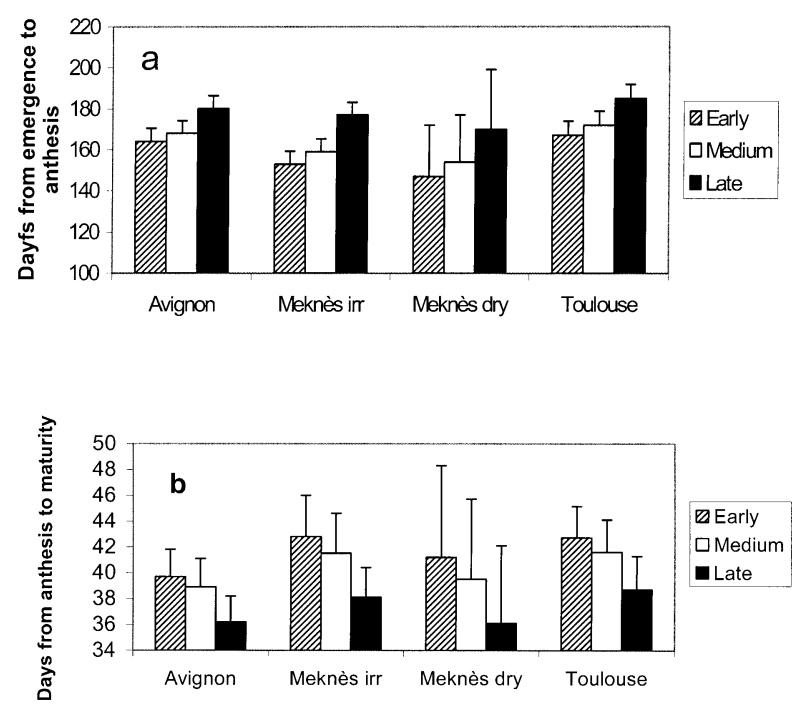

Figure 1. Duration of pre- and post-anthesis phases for 3 cultivars (early, medium, late) and 4 water environments (rainfed: Avignon, Meknès, Toulouse; irrigated: Meknès) - Bars indicate the upper value of standard deviation. (a) days from emergence to anthesis; (b) days from anthesis to physiological maturity.

With supplemental irrigation, maturity was delayed by 1 (Avignon, Toulouse) and 3 days (Meknès). The length of the grain-filling period (DRP-MAT) ranged from 36 to 43 days in rainfed conditions according to soil water deficit and air temperature (Fig. 1b). It lasted 4-5 days more with the early-maturing cultivar than with the late one. In Avignon, the duration of the DRP-MAT was the shortest. The variability was at its maximum in Meknès under rainfed conditions.

In this study, a late-maturing sorghum genotype was considered (1800 degree-days in base $6{ }^{\circ} \mathrm{C}$ from emergence to maturity). Grain maturity occurred on 7 September (Toulouse) and 9 August (Meknès) under rainfed conditions which resulted in a crop length duration (LEV-MAT) of 250 and 221 days, respectively.

The standard crop parameters suggested for wheat and sorghum [9] were kept unchanged in this simulation study. 
Table III. Description of scenarios under simulation.

\begin{tabular}{|c|c|c|c|c|c|c|}
\hline & Climate & $\begin{array}{l}\text { Initial soil water } \\
\text { (\% ASW) }\end{array}$ & Crop & Cultivar & Irrigation & Plant density (plants $/ \mathrm{m}^{2}$ ) \\
\hline $\begin{array}{l}\text { Cultivar earliness } \\
\text { Section } 3.2\end{array}$ & $\begin{array}{l}\text { Avignon (A), Meknès } \\
\text { (M) Toulouse (T) }\end{array}$ & 50 & Wheat & $\begin{array}{l}\text { Early (E), Medium } \\
\text { (M) Late (L) }\end{array}$ & $\begin{array}{l}\text { Rainfed vs. } \\
\text { Automatic }\end{array}$ & 250 \\
\hline $\begin{array}{l}\text { Supplemental irrigation } \\
\text { Section } 3.3\end{array}$ & $\mathrm{~A}, \mathrm{M}, \mathrm{T}$ & 50 & Wheat & $\mathrm{E}, \mathrm{M}, \mathrm{L}$ & $\begin{array}{l}\text { Rainfed vs. } \\
\text { Automatic }\end{array}$ & 250 \\
\hline Soil water at planting & $\mathrm{M}, \mathrm{T}$ & $10,25,50,75,100$ & Wheat & $\mathrm{M}$ & Rainfed & 250 \\
\hline Section 3.4 & $\mathrm{M}, \mathrm{T}$ & $10,25,50,75,100$ & Sorghum & $1800^{\text {(a) }}$ & Rainfed & 30 \\
\hline $\begin{array}{l}\text { Rapid canopy closure } \\
\text { Sections } 3.5-3.6\end{array}$ & $\mathrm{M}, \mathrm{T}$ & 50 & Wheat & E, L & Rainfed & $150,250,450$ \\
\hline $\begin{array}{l}\text { Crop management } \\
\text { system } \\
\text { Section } 3.7\end{array}$ & M & 50 & Wheat & $\mathrm{E}, \mathrm{L}$ & $\begin{array}{l}\text { Rainfed vs. } \\
\text { Automatic }\end{array}$ & $150,250,450$ \\
\hline
\end{tabular}

(a) Length of the growing season: degree-days (base $6{ }^{\circ} \mathrm{C}$, air temperature) from emergence (LEV) to maturity (MAT).

Table IV. Correlations between wheat grain yield (GY) and the components of crop productivity in water-limited environments according to the Passioura framework [33] ( 3 climatic environments $\times 3$ cultivars, rainfed conditions). Es $+\mathrm{T}$, water use; Es/T, soil evaporation/transpiration; TE, transpiration efficiency; $\mathrm{HI}$, harvest index. Correlations are significant at $P<0.001(\mathrm{n}=294)$.

\begin{tabular}{ccccc}
\hline & Es $+\mathrm{T}$ & Es / T & TE & HI \\
\hline $\mathrm{r}$ & +0.489 & -0.655 & +0.447 & +0.917 \\
\hline
\end{tabular}

\subsection{Scenario analysis}

The different crop management strategies which were analyzed are presented in Table III. Their consequences on grain yield, yield components and water use were compared using the framework of Passioura [33], on the basis of cumulative frequency distribution (CFD) and means. The lower risk option of two alternatives (in terms of agronomy) was determined on the basis of the relative position of their CFD curves [3, 23, 32, 39].

\section{RESULTS}

\subsection{Variability of grain yield and water availability}

Wheat grain yield (GY) ranged from 0 to $11 \mathrm{t} /$ ha according to natural water resources. The ET/ETo ratio which expresses the level of water satisfaction ranged from 0.5 to 1 . The average value over 30-35 yrs was $0.71,0.83$ and 0.90 for Meknès, Avignon and Toulouse, respectively. It accounted for $43 \%$ of the GY variability under rainfed management.

\subsection{Escaping water stress under rainfed conditions by the choice of wheat cultivar}

In the 2 Mediterranean environnements (Avignon, Meknès), it clearly appears that late cultivars have major disadvantages as compared with the early and medium types (Fig. 2a, b). In Toulouse, the success of early genotypes was extremely dependent upon water availability and temperature regime during grain filling (Fig. 2c). In half the years, a late-maturing cultivar
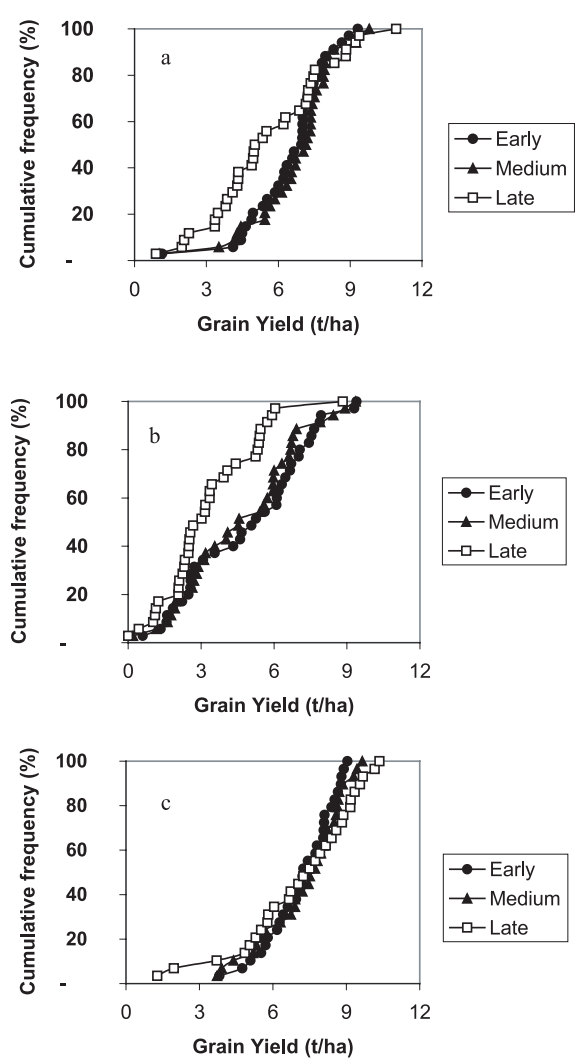

Figure 2. Cumulative distribution function for grain yield of 3 rainfed wheat cultivars differing by earliness at anthesis: (a) Avignon; (b) Meknès; (c) Toulouse.

was the best choice; the early cultivar was the less risky option 1 year out of 4 . Sowing a medium type is the best choice in such a fluctuating situation.

Accordingly to the Passioura framework, GY clearly increased with harvest index and Es/T in rainfed conditions (Tab. IV). Although significant, the correlations between GY and water use and GY and TE were lower than with $\mathrm{HI}$ and Es/T. 
Table V. Grain yield and water use components of 3 wheat cultivars under rainfed (Rfd) and irrigated (Irr) management. Standard deviation for GY indicated between brackets.

\begin{tabular}{|c|c|c|c|c|c|c|c|c|c|c|c|c|c|c|c|c|c|}
\hline \multirow{2}{*}{ Weather } & \multirow{2}{*}{ Cultivar } & \multirow{2}{*}{$\begin{array}{l}\text { Irrigation } \\
\quad(\mathrm{mm})\end{array}$} & \multicolumn{2}{|c|}{$\begin{array}{l}\text { GY } \\
(\mathrm{t} / \mathrm{ha})\end{array}$} & \multicolumn{2}{|c|}{$\begin{array}{l}\text { DM } \\
(\mathrm{t} / \mathrm{ha})\end{array}$} & \multicolumn{2}{|c|}{$\mathrm{HI}$} & \multicolumn{2}{|c|}{$\begin{array}{l}\text { ET } \\
(\mathrm{mm})\end{array}$} & \multicolumn{2}{|c|}{ Es / T } & \multicolumn{2}{|c|}{$\begin{array}{c}\mathrm{TE} \\
(\mathrm{kg} / \mathrm{mm})\end{array}$} & \multirow{2}{*}{$\begin{array}{c}\text { Water Stress } \\
\text { Grain Filling }\end{array}$} & \multicolumn{2}{|c|}{ ET/ETo } \\
\hline & & & $\mathrm{Rfd}$ & Irr & $\mathrm{Rfd}$ & Irr & Rfd & Irr & Rfd & Irr & Rfd & Irr & $\mathrm{Rfd}$ & Irr & & $\mathrm{Rfd}$ & Irr \\
\hline \multirow[t]{3}{*}{ Avignon } & Early & 86 & $\begin{array}{c}6.49 \\
(1.79)\end{array}$ & $\begin{array}{c}7.69 \\
(1.69)\end{array}$ & 15.3 & 18.4 & 0.423 & 0.419 & 336 & 405 & 0.45 & 0.36 & 64.9 & 61.0 & 0.71 & 0.88 & 0.99 \\
\hline & Medium & 127 & $\begin{array}{c}6.63 \\
(1.76)\end{array}$ & $\begin{array}{c}8.00 \\
(1.72)\end{array}$ & 15.7 & 19.7 & 0.422 & 0.407 & 347 & 439 & 0.44 & 0.33 & 64.0 & 59.0 & 0.61 & 0.85 & 0.99 \\
\hline & Late & 180 & $\begin{array}{c}5.48 \\
(2.41)\end{array}$ & $\begin{array}{c}7.47 \\
(2.15)\end{array}$ & 16.5 & 21.8 & 0.332 & 0.343 & 354 & 501 & 0.47 & 0.29 & 62.6 & 55.5 & 0.46 & 0.77 & 0.98 \\
\hline \multirow[t]{3}{*}{ Meknès } & Early & 178 & $\begin{array}{c}4.97 \\
(2.46)\end{array}$ & $\begin{array}{c}7.97 \\
(1.59)\end{array}$ & 14.4 & 20.5 & 0.346 & 0.389 & 377 & 532 & 0.46 & 0.30 & 52.5 & 49.5 & 0.49 & 0.77 & 0.99 \\
\hline & Medium & 250 & $\begin{array}{c}4.69 \\
(2.37)\end{array}$ & $\begin{array}{c}8.53 \\
(1.25)\end{array}$ & 14.5 & 21.8 & 0.324 & 0.392 & 379 & 576 & 0.47 & 0.28 & 52.9 & 48.2 & 0.39 & 0.73 & 0.98 \\
\hline & Late & 342 & $\begin{array}{c}3.32 \\
(1.90)\end{array}$ & $\begin{array}{c}8.71 \\
(1.81)\end{array}$ & 14.4 & 24.2 & 0.230 & 0.360 & 378 & 666 & 0.51 & 0.24 & 54.2 & 45.3 & 0.27 & 0.64 & 0.98 \\
\hline \multirow[t]{3}{*}{ Toulouse } & Early & 46 & $\begin{array}{c}7.19 \\
(1.35)\end{array}$ & $\begin{array}{c}7.56 \\
(1.07)\end{array}$ & 17.2 & 18.5 & 0.417 & 0.408 & 372 & 403 & 0.43 & 0.38 & 65.9 & 63.9 & 0.85 & 0.94 & 0.99 \\
\hline & Medium & 62 & $\begin{array}{c}7.31 \\
(1.64)\end{array}$ & $\begin{array}{c}7.79 \\
(1.22)\end{array}$ & 17.7 & 19.5 & 0.413 & 0.399 & 383 & 429 & 0.41 & 0.36 & 64.7 & 61.9 & 0.77 & 0.91 & 0.99 \\
\hline & Late & 120 & $\begin{array}{c}7.15 \\
(2.28)\end{array}$ & $\begin{array}{c}8.40 \\
(2.13)\end{array}$ & 18.3 & 21.4 & 0.391 & 0.392 & 401 & 483 & 0.41 & 0.32 & 63.4 & 58.9 & 0.61 & 0.85 & 0.99 \\
\hline
\end{tabular}

Late cultivars resulted in more water use (ET) and higher total biomass (DM) in Avignon and Toulouse but in Meknès no difference was observed with the duration of the growing season as available water was more limited as indicated by ET/ ETo which ranged from 0.64 to 0.77 in semiarid conditions (Tab. V). TE was highest for the early cultivar in Toulouse and Avignon but for the late cultivar in Meknès. The Es/T ratio was the lowest for the early cultivar in Meknès while in Avignon and Toulouse, more soil evaporation was observed with latematuring cultivars. HI was always lower for the late genotypes in relation to a shorter grain-filling duration and a higher waterstress index during that period (Tab. V).

In Meknès, the general low yield level resulted from a high contribution of soil evaporation to ET (32\%), a low transpiration efficiency $(53 \mathrm{~kg} / \mathrm{mm})$ and a low harvest index (0.30). ET was higher than in Avignon because of more precipitation (Tab. I).

\subsection{Increasing available water: supplemental irrigation for wheat}

Using the same decision rule for each location and wheat cultivar, the application of STICS over 30 years resulted in an increase in supplemental irrigation volume with the aridity index (76 $\mathrm{mm}$ in Toulouse, $131 \mathrm{~mm}$ in Avignon and $257 \mathrm{~mm}$ in Meknès) and the length of the growing season (104 mm for the early type, $146 \mathrm{~mm}$ for medium and $214 \mathrm{~mm}$ for late) (Tab. V). The choice of an early-maturing cultivar resulted in lower plant water requirements.

The yield gain with this decision rule was improved in the same way (from $0.37 \mathrm{t} / \mathrm{ha}$ in Toulouse with an E type to $5.39 \mathrm{t} / \mathrm{ha}$ in Meknès with a L type). The irrigation efficacy (GY irrigated
- GY rainfed /IRR) increased with the aridity index; it was maximum for the early cultivar in Avignon $(14.0 \mathrm{~kg} / \mathrm{mm})$ and Meknès $(16.8 \mathrm{~kg} / \mathrm{mm})$ and for the late cultivar in Toulouse (10.4 kg/mm).

With supplemental irrigation, the superiority of the latematuring cultivar over the early type was observed in $53 \%$ (Avignon), 69\% (Toulouse) and 71\% (Meknès) of the weather situations (Fig. 3a-c). When irrigation was fully available, the longer growing season resulted in the best GY performance, except in Avignon where the yield ranking under rainfed management did not change with irrigation.

With irrigation, ET increased by 8 to $76 \%$ (according to cultivar and location) because of more available water throughout the growing season. TE was always higher under rainfed conditions. The Es/T ratio was reduced with irrigation because of a rapid canopy closure and a longer duration of active LAI when water was available. HI was higher with irrigation in Meknès and for the late-maturing cultivar, whereas under moderate stress conditions (Avignon and Toulouse, E and M cultivars), HI was always higher under rainfed conditions.

Plant $N$ uptake increased with irrigation from 6 (E, Toulouse) to $44 \mathrm{~kg} / \mathrm{ha}$ (L, Meknès): this came from a substantial increase in $\mathrm{N}$ mineralization with soil temperature when water was available (from 100-110 kg/ha under rainfed conditions to $120-170 \mathrm{~kg} / \mathrm{ha}$ under irrigated conditions). More $\mathrm{N}$ leaching (up to $24 \mathrm{~kg} / \mathrm{ha}$ ) occurred with automatic irrigation. In the conditions of this simulation study, STICS did not identify significant differences in nitrogen stress between irrigated and rainfed conditions. Under irrigation, the highest yields were obtained in Meknès as a result of more ET and a reduction of soil evaporation because of a more rapid canopy closure. The increase in $\mathrm{N}$ uptake resulted in more grain number/ $\mathrm{m}^{2}(+27 \%)$ with spring 

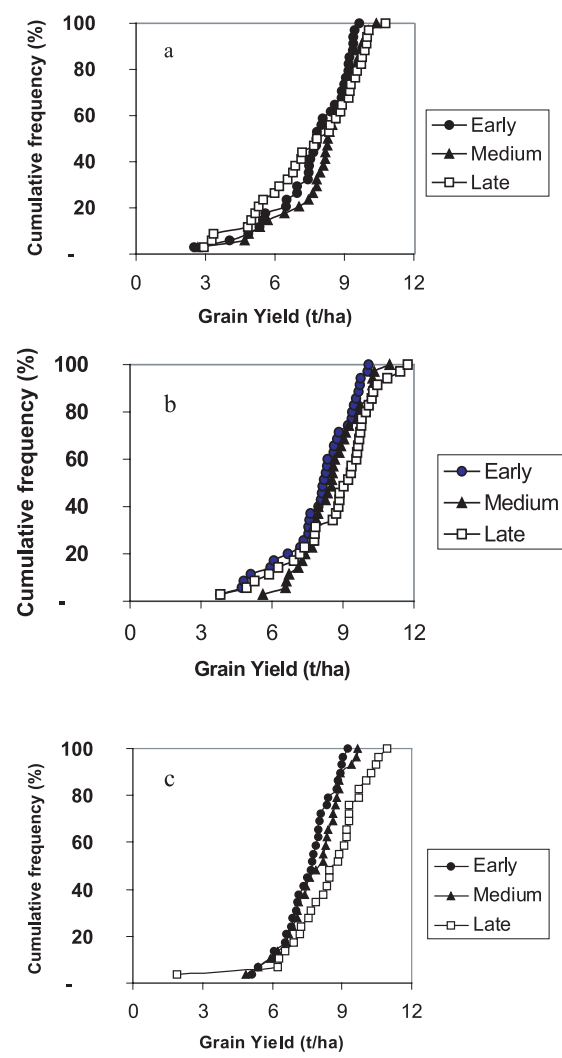

Figure 3. Cumulative distribution function for grain yield of 3 irrigated wheat cultivars differing by earliness at anthesis: (a) Avignon; (b) Meknès; (c) Toulouse.

irrigation. TE and HI remained lower in Meknès, as under rainfed conditions, because of high evaporative demand and high temperature.

\subsection{Increasing available water: effect of soil water content (SWC) at crop sowing}

\subsubsection{Winter wheat (rainfed)}

The initial level of soil water recharge at wheat sowing in fall had no influence on grain yield in Toulouse. Only in 1989, where a severe drought occurred, a significant reduction (-14\%) was observed when soil water was only refilled at $10 \%$ in early
November. Leaving the soil at the soil water holding capacity at wheat sowing resulted in more $\mathrm{N}$ leaching $(18 \mathrm{~kg} / \mathrm{ha}$ vs $9 \mathrm{~kg} / \mathrm{ha})$ with negative impacts on grain number $/ \mathrm{m}^{2}$.

The effect was more obvious in Meknès: average yield was reduced by $10 \%$ on average when leaving the soil at $10 \%$ of available soil water (ASW) at wheat sowing. In 7 years out of 35 , the yield reduction was less than $10 \%$. Yield reduction resulted from lower ET, higher Es/T and lower HI (Tabl. VI). Transpiration efficiency and the ET/ETo ratio did not differ with initial SWC. A reduction of LAI by $9 \%$ was responsible for this adjustment to the natural water resource. This resulted in a lower value of water stress during grain filling (turfac $=$ 0.43 vs 0.38 for SWC at field capacity) and a lower water drainage amount in those situations limited by initial soil water.

\subsubsection{Sorghum (rainfed)}

The impact of soil water content (SWC) on 1st March was higher for spring-sown crops. Grain yield was reduced by $3 \%$ in Toulouse but by $25 \%$ in Meknès when SWC fell from field capacity to $10 \%$ of available soil water (Tab. VII). The reductions were 2,6 , and $17 \%$ for $75 \%, 50 \%$ and $25 \%$ of ASW, respectively. The risk of not detecting yield differences with the level of initial SWC was about $30 \%$ in Meknès (Fig. 4). For these specific soil depth and hydraulic properties, the critical level of SWC for planting sorghum without significant yield penalties was close to $50 \%$ of ASW in early spring. Yield reduction with lower SWC resulted from lower ET and higher Es/T. This ratio increased up to 0.90 in Meknès. This resulted from a slower canopy closure with low initial SWC, especially under semi-arid conditions. In Meknès, maximal LAI was drastically reduced in such conditions: $-27 \%$ of LAI at field capacity. Unlike wheat, the harvest index increased for sorghum with water deficit. As in wheat, the reduction of LAI with water deficit resulted in similar values of ET/ETo with initial soil water within each climatic context and a reduction of drainage.

\subsection{Reducing water loss by evaporation through rapid canopy closure}

Increasing wheat plant density from 150 to 450 plants $/ \mathrm{m}^{2}$ had limited impact on yield in Toulouse while a depressive effect was observed in Meknès, especially with late-maturing cultivars (Tab. VIII). A slight increase in ET (4\%) was observed together with a reduction of Es/T (from 0.50 to 0.41 ). However, TE was reduced by $6 \%$ and $\mathrm{HI}$ by $8 \%$. Increasing plant density had limited effects on the occurrence of water stress before

Table VI. Grain yield and water use components of a rainfed medium wheat cultivar for 2 levels of soil water content on 20 October (Meknès conditions). FC = soil water content at field capacity (100\% ASW). Standard deviation for GY indicated between brackets.

\begin{tabular}{lccccccccc}
\hline & GY (t/ha) & DM (t/ha) & HI & $\begin{array}{c}\text { LAI } \\
\text { max }\end{array}$ & ET (mm) & Es/T & TE (kg/mm) $\begin{array}{c}\text { Water Stress } \\
\text { Grain Filling }\end{array}$ & $\begin{array}{c}\text { Drainage } \\
\text { ET/ETo } \\
(\mathrm{mm}) \\
20 / 10-1 / 08\end{array}$ \\
\hline $\begin{array}{l}\text { Meknès } \\
10 \% \text { ASW }\end{array}$ & $\begin{array}{c}4.32 \\
(2.37)\end{array}$ & 13.7 & 0.314 & 5.35 & 367 & 0.52 & 53.0 & 0.43 & 0.74 \\
$\begin{array}{l}\text { Meknès } \\
\text { FC }\end{array}$ & $\begin{array}{l}4.80 \\
(2.36)\end{array}$ & 14.5 & 0.330 & 5.84 & 381 & 0.44 & 53.1 & 0.38 & 0.73 \\
\hline
\end{tabular}


Table VII. Grain yield and water use components of a rainfed sorghum cultivar for 2 levels of soil water content on 1st March. Standard deviation for GY indicated between brackets.

\begin{tabular}{|c|c|c|c|c|c|c|c|c|c|}
\hline & GY (t/ha) & $\mathrm{HI}$ & $\begin{array}{l}\text { LAI } \\
\max \end{array}$ & $\mathrm{ET}(\mathrm{mm})$ & $\mathrm{Es} / \mathrm{T}$ & $\mathrm{TE}(\mathrm{kg} / \mathrm{mm})$ & $\begin{array}{l}\text { Water Stress } \\
\text { Grain Filling }\end{array}$ & ET/ETo & $\begin{array}{c}\text { Drainage } \\
(\mathrm{mm}) \\
1 / 03-15 / 12\end{array}$ \\
\hline $\begin{array}{l}\text { Meknès } \\
10 \% \text { ASW }\end{array}$ & $\begin{array}{c}3.42 \\
(1.35)\end{array}$ & 0.831 & 2.66 & 215 & 0.90 & 33.5 & 0.10 & 0.39 & 21 \\
\hline $\begin{array}{l}\text { Meknès } \\
50 \% \text { ASW }\end{array}$ & $\begin{array}{c}4.29 \\
(0.78)\end{array}$ & 0.815 & 3.27 & 243 & 0.60 & 34.6 & 0.10 & 0.42 & 46 \\
\hline $\begin{array}{l}\text { Meknès } \\
\text { FC }\end{array}$ & $\begin{array}{c}4.58 \\
(0.52)\end{array}$ & 0.791 & 3.64 & 260 & 0.51 & 33.9 & 0.10 & 0.41 & 105 \\
\hline $\begin{array}{l}\text { Toulouse } \\
10 \% \text { ASW }\end{array}$ & $\begin{array}{c}6.04 \\
(1.50)\end{array}$ & 0.629 & 3.95 & 354 & 0.60 & 44.0 & 0.40 & 0.69 & 58 \\
\hline $\begin{array}{l}\text { Toulouse } \\
\text { FC }\end{array}$ & $\begin{array}{c}6.24 \\
(1.47)\end{array}$ & 0.567 & 4.22 & 377 & 0.49 & 43.2 & 0.37 & 0.70 & 175 \\
\hline
\end{tabular}

Table VIII. Grain yield and water use components of rainfed wheat for 3 plant densities $\left(150,250,450\right.$ plants $\left./ \mathrm{m}^{2}\right)$. Standard deviation for GY indicated between brackets.

\begin{tabular}{|c|c|c|c|c|c|c|c|c|c|c|c|}
\hline & Cultivar & $\begin{array}{l}\text { Plant } \\
\text { density }\end{array}$ & GY (t/ha) & $\mathrm{DM}(\mathrm{t} / \mathrm{ha})$ & $\mathrm{HI}$ & ET (mm) & $\mathrm{Es} / \mathrm{T}$ & $\mathrm{TE}(\mathrm{kg} / \mathrm{mm})$ & $\begin{array}{l}\text { Water stress } \\
\text { vegetative }\end{array}$ & $\begin{array}{l}\text { Water stress } \\
\text { grain filling }\end{array}$ & ET/ETo \\
\hline \multirow[t]{6}{*}{ Toulouse } & \multirow[t]{3}{*}{ Early } & 150 & $\begin{array}{c}7.09 \\
(1.20)\end{array}$ & 16.8 & 0.422 & 359 & 0.48 & 69.2 & 1 & 0.89 & 0.96 \\
\hline & & 250 & $\begin{array}{c}7.19 \\
(1.35)\end{array}$ & 17.2 & 0.417 & 372 & 0.43 & 65.9 & 0.99 & 0.85 & 0.94 \\
\hline & & 450 & $\begin{array}{c}7.20 \\
(1.46)\end{array}$ & 17.6 & 0.408 & 382 & 0.38 & 63.3 & 0.99 & 0.81 & 0.92 \\
\hline & \multirow[t]{3}{*}{ Late } & 150 & $\begin{array}{c}7.13 \\
(2.20)\end{array}$ & 17.9 & 0.398 & 394 & 0.45 & 65.2 & 0.99 & 0.64 & 0.87 \\
\hline & & 250 & $\begin{array}{c}7.15 \\
(2.28)\end{array}$ & 18.3 & 0.391 & 401 & 0.41 & 63.4 & 0.99 & 0.60 & 0.85 \\
\hline & & 450 & $\begin{array}{c}7.15 \\
(2.32)\end{array}$ & 18.7 & 0.383 & 408 & 0.36 & 61.6 & 0.99 & 0.58 & 0.83 \\
\hline \multirow[t]{6}{*}{ Meknès } & \multirow[t]{3}{*}{ Early } & 150 & $\begin{array}{c}5.23 \\
(2.28)\end{array}$ & 14.1 & 0.370 & 370 & 0.50 & 54.9 & 0.96 & 0.55 & 0.82 \\
\hline & & 250 & $\begin{array}{c}4.97 \\
(2.46)\end{array}$ & 14.4 & 0.346 & 377 & 0.46 & 52.5 & 0.94 & 0.49 & 0.77 \\
\hline & & 450 & $\begin{array}{c}4.74 \\
(2.66)\end{array}$ & 14.7 & 0.323 & 383 & 0.41 & 50.2 & 0.93 & 0.44 & 0.72 \\
\hline & \multirow[t]{3}{*}{ Late } & 150 & $\begin{array}{c}3.59 \\
(1.81)\end{array}$ & 14.1 & 0.255 & 373 & 0.56 & 56.0 & 0.92 & 0.30 & 0.69 \\
\hline & & 250 & $\begin{array}{c}3.32 \\
(1.90)\end{array}$ & 14.4 & 0.230 & 378 & 0.51 & 54.2 & 0.90 & 0.27 & 0.64 \\
\hline & & 450 & $\begin{array}{c}3.12 \\
(2.07)\end{array}$ & 14.8 & 0.211 & 383 & 0.47 & 52.5 & 0.89 & 0.26 & 0.60 \\
\hline
\end{tabular}

flowering but it was responsible for major differences between stand densities during grain filling; more water stress occurred during the post-floral period with increasing plant density under rainfed conditions.

In Toulouse, the lowest Es/T ratio (0.36) was observed for the late cultivar with 450 plants $/ \mathrm{m}^{2}$ while in Meknès the early cultivar at high density (0.41) was the most efficient at reducing the contribution of Es to total ET.
A simulation during the whole growing season for a specific environment (Meknès, 1973) illustrated that total evaporation was greater on early cultivars and low densities (because of poor soil covering): $125 \mathrm{~mm}$ (early cultivar, $150 \mathrm{plants} / \mathrm{m}^{2}$ ) vs. $105 \mathrm{~mm}$ (late cultivar, 450 plants $/ \mathrm{m}^{2}$ ). On the other hand, the Es/T ratio was lower when considering only the winter months for the early-growing genotype as compared with the late genotype (Fig. 5). 


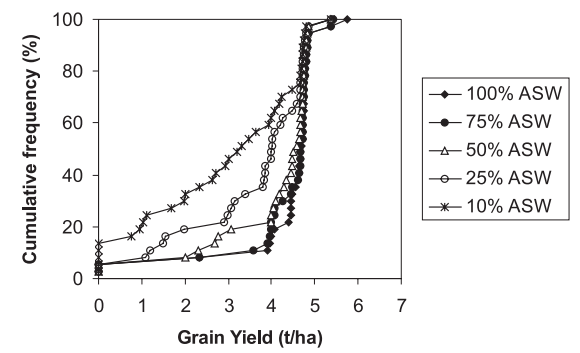

Figure 4. Cumulative distribution function for sorghum yield as related to soil-stored water in spring (\% of available soil water, ASW) Meknès (1960-1996).

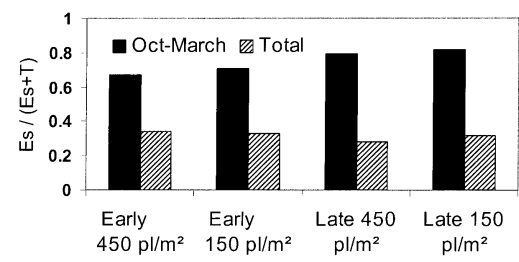

Figure 5. Contribution of soil evaporation to total ET for the winter period (October-March) and total growing season in relation to crop management (Meknès, 1973): 2 cultivars (Early, Late), 2 plant densities $\left(150,450\right.$ plants $\left./ \mathrm{m}^{2}\right)$.

\subsection{Increasing available water for grain filling through crop rationing}

Reducing crop demand in the vegetative period to save water for anthesis and grain filling is a management goal often mentioned in water-limited environments.

Using the results observed in Toulouse (1972-2001) with a late-maturing cultivar, we observed that it could be recommended to increase the $\mathrm{T}$ post-anthesis / T growing season ratio to $25 \%$ to maximize the harvest index and consequently grain yield (Fig. 6). This could result from lower plant density, or a favorable rainfall distribution pattern or rooting extraction pattern [29].

We tested if decreasing Es/T by rapid canopy closure was compatible or not with the objective of saving water for grain filling instead of promoting high grain number. According to Figure 7, these two objectives did not appear to be adverse. Situations where soil evaporation was significant relatively to plant transpiration resulted in a greater water-stress index and a lower HI. However, distinct relations were obtained according to crop rationing resulting from plant density (150 vs. 450 plants $\left./ \mathrm{m}^{2}\right)$. Although increasing plant density was more efficient at reducing Es/T, it increased the water-stress index during grain filling under rainfed conditions (Tab. VIII).

\subsection{Combining different strategies in a crop management system: cultivar earliness, plant density and supplemental irrigation}

Evidence of interactions beween water availability, plant density and duration of the growing season was demonstrated

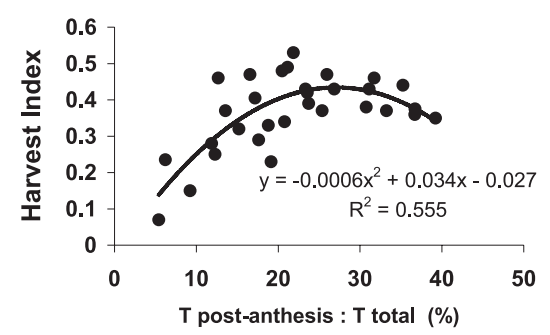

Figure 6. Relationship between harvest index and the fraction of water transpired after anthesis: Toulouse, rainfed conditions, latematuring cultivar (1972-2001).

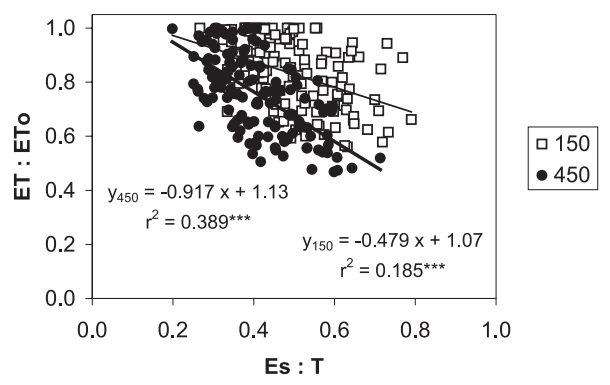

Figure 7. Relation between ET: ETo (water satisfaction ratio) and Es: T for 2 cultivars (early, late), 2 plant densities $\left(150,450 \mathrm{pl} / \mathrm{m}^{2}\right)$ and 2 climates (Meknès, Toulouse) - rainfed conditions.

by the use of crop simulation. The exercise was applied only to the Meknès conditions (Fig. $8 \mathrm{a}-\mathrm{c}$ ).

Where low densities and early genotypes were the optimal scheme in rainfed systems, adverse effects were observed in fully irrigated systems.

The reduction of Es/T was maximal for irrigated, high densities and late genotypes while early genotypes were more efficient in rainfed systems. This effect was nevertheless not sufficient in itself to explain the yield variation: the ET/ETo ratio illustrates the positive effect of crop rationing and escaping strategies for water economy and yield stability in rainfed systems. The reduction of LAI in early cultivars and low density was a way to decrease significantly the level of plant water stress.

Under irrigated conditions, duration of the growing period and light interception were the limiting factors: late genotypes and high densities resulted in the highest yields.

\section{DISCUSSION}

\subsection{Qualitative validation of the effects of crop management on yield and water use in water-limited environments}

Although no direct comparisons were attempted with field observations, this simulation exercise contributed to a qualitative evaluation of the STICS model. The performance of the 

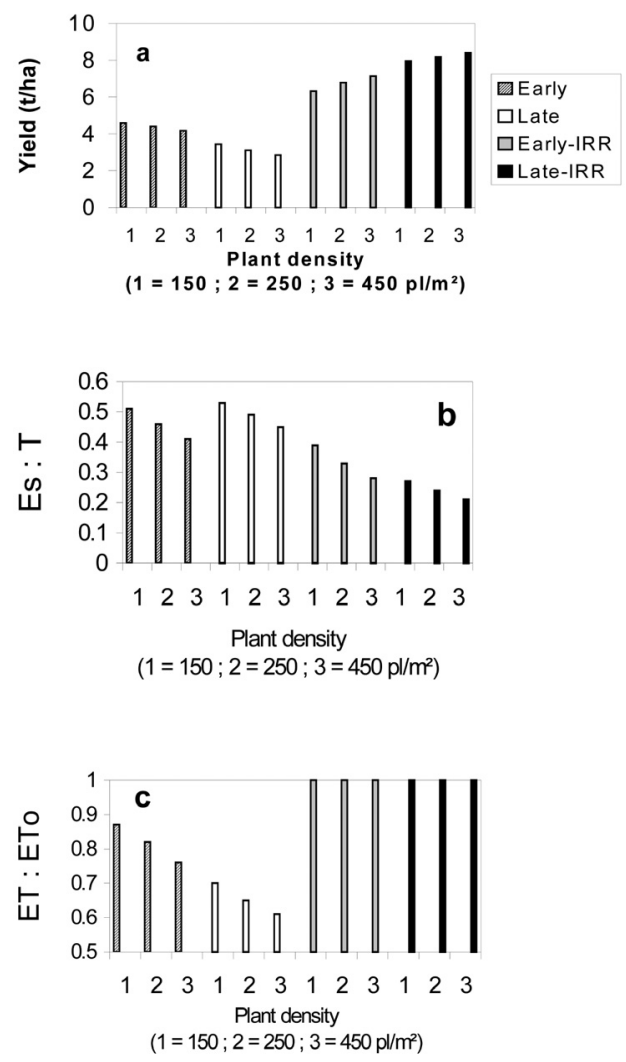

Figure 8. Effects of wheat phenology, plant density and irrigation on (a) grain yield (GY), (b) Es: T ratio and (c) water satisfaction ratio (ET: ETo) under semi-arid conditions (Meknès).

model in representing consistently interactions between water availability (soil, rain and irrigation), crop phenology and the plant water-use pattern was illustrated through the different case studies.

Genotypic variation in growth duration is the most obvious means of matching seasonal transpiration with the water supply and thus maximizing water transpired [29]. For a range of annual crops, simulation studies were often carried out to determine the optimal growth position and duration (cultivar phenology or sowing date) considering the seasonal rainfall distribution and amount [1, 19, 31, 32, 36, 37]. We confirmed in this study that early anthesis gave higher yields and greater stability than later anthesis when rain did not occur in May and June (as in Meknès). As early flowering enabled a cultivar to escape drought during the critical reproductive stages, the harvest index was then improved. In contrast, in Toulouse, an early-maturing cultivar did not result each year in the highest yield. In conditions of intermittent stress (ex. Toulouse), water deficit can occur at any time and with varying intensities between emergence and maturity, while in conditions of terminal stress (ex. Meknès), where crops are grown on soil water mainly stored during winter, a progressive and systematic soil moisture depletion was observed in spring. Short season varieties are beneficial when rainfall is reasonably predictable (as in Meknès) but in unpredictable environments, potentially transpirable water may be left in the soil at maturity in better years and yield may be sacrificed. Several examples are given by Ludlow and Muchow [29] where yields of early-maturing cultivars were higher only when yields were reduced by at least $40 \%$ by low water supply. In Israel, Blum [6] demonstrated the interaction between water availability and optimal growth duration for wheat: under conditions of water deficit $(G Y<$ $3 \mathrm{t} \mathrm{ha}^{-1}$ ), the correlation between yield and days to heading of 12 cultivars was negative while under well-watered conditions $\left(\mathrm{GY}>6 \mathrm{t} \mathrm{ha}^{-1}\right)$, late-flowering cultivars had a yield advantage; under mild stress, mean yield was not related to growth duration. In contrast, later flowering may be beneficial where drought occurs early in the growing season or where grain maturation is delayed until after the return of rain (summer storms). Depending on the rainfall pattern, early- or late-maturing wheat genotypes succeeded differently, which was properly represented by the STICS model. In semi-arid conditions, shortening the growing period is generally to be preferred (escaping strategy) while in sub-humid and humid conditions, the reduction of potential production is more detrimental than the risk of severe yield limitation by water stress.

In Toulouse and Meknès, wheat was only slightly affected by SWC at crop sowing. In the simulated environments, crops sown in late fall (or winter) receive rainfall which is variable but often sufficient to cover water needs until anthesis, with fluctuations resulting from the degree of recharge during the previous winter [22]. But for spring-sown crops, the initial soil moisture may be more critical for grain yield (Fig. 4). In Australia, for instance, the level of soil-stored water is a decision indicator for the choice of fallow vs. sorghum planting [32]. In Meknès, sorghum yield always increased with initial soil water content but more drainage was observed when the initial profile was at field capacity. Maximizing SWC at planting may sometimes be detrimental to yield. In the study of Aboudrare et al. [2] in Meknès, where a range of SWC at sunflower planting was compared, it appeared that if leaf area index at the early bud stages and cumulative ET increased with SWC, grain yield and water-use efficiency were not maximal for the highest SWC. Sunflower did not succeed in using water sparingly throughout the season: transpiration during grain filling was limited when excessive LAI resulted from high initial water. Crop rationing resulting from a moderate initial SWC was an objective for sunflower management on soil-stored water.

Under Mediterranean conditions, it is apparent that 30-60\% of the seasonal ET may be lost as evaporation from the soil surface [27]. In our simulations, with varying locations, plant densities and cultivars, the Es/ET ratio ranged from 19 to $43 \%$ under rainfed management (17-38\% for irrigated wheat). Under the assumption of Qo $=0$, the average value of soil evaporation was $110 \mathrm{~mm}$ without irrigation $(\mathrm{Es} / \mathrm{T}=30 \%)$; with values up to Qo $=15$, more Es occurred $(225 \mathrm{~mm})$ and the Es/T ratio reached $50 \%$. As this gives more significance to soil evaporation's contribution to the water balance, we may expect earlier and more severe water deficit when increasing Qo. However, the general conclusions on the crop management effects should not be seriously contested when changing the evaporation contribution to seasonal ET.

Rapid canopy closure is a major management objective and a factor of yield improvement in short growing environments as is in the case in hot and dry conditions. Plant characteristics such as early vigor and crop morphology, and management 
practices such as early sowing, increased fertilizer input, planting density and reduced row width, which increase early growth, have been shown to decrease Es/T [17, 18, 20, 38]. In rainfed conditions, it increases TE in periods of low water deficit and it decreases the ratio Es/T because of fast soil covering. From the STICS simulations, it was concluded that early genotypes, high plant density and initial water availability concurred in a reduction of the contribution of Es to ET, especially during the first part of the season when wheat has low LAI and the soil surface is frequently wetted by rainfall. TE is generally reported as higher during periods of low vapor pressure deficit (VPD) as in the cool winter months [18, 29]: both in irrigated and rainfed wheat, early cultivars resulted in higher values of TE except in Meknès (rainfed) where TE was higher for the late cultivar.

Modifying the plant population can have large beneficial effects on the reduction of Es/T. However, when water is short, low plant populations are generally recommended and practised in order to maximize the available water per plant, in spite of an increase in Es/T. For instance, Anderson [4] showed that the optimal density for triticale varied from 80 to 190 plants $/ \mathrm{m}^{2}$ for grain yields ranging from 2.1 to $6.9 \mathrm{t} \mathrm{ha}^{-1}$ depending upon the season's rainfall. In situations with terminal drought, excessive LAI and grain number could result in a risk of rapid soil water depletion and a high water-stress level at the most sensitive crop stages [24]. The STICS simulations clearly indicated that increasing plant density decreased Es/T but an increased water-stress index during grain filling with detrimental consequences on the harvest index [26, 33].

Passioura [33] concluded that the grain yield of wheat growing on a fixed and limiting supply of water can be substantially increased by forcing the plants to save water for post-anthesis growth. In his experiment, HI increased with the fraction of water transpired after anthesis. We confirmed this relation with STICS in the climatic context of Toulouse (Fig. 6). However, the ratio of water used before and after anthesis in each environment relates to the severity of water stress in the post-anthesis period and Loss and Siddique [27] reported values ranging from 15 to $35 \%$ for different regions of Australia.

\subsection{Limitations of the simulation exercise}

Many simplifications and rough assumptions were accepted in this study both on biological and decisional points of view. Simulated yields were probably overestimated (especially with irrigation). Increasing water, nitrogen and plant density in the wheat crop often increase the risks of disease attacks and plant lodging, which are only partly controlled with chemicals and which were ignored by the model. The effect of early drought on crop emergence and establishment was incompletely described by STICS. If the delay in emergence date was simulated, seedling losses and uneven emergence were not considered. In addition, in dry seedbeds, successive flushes of seedlings are observed in relation to seed placement and rainfall events. The way the model simulates a reduction of plant density is an oversimplification of the emergence process. As in other simulations studies [39], low plant densities appeared as good technical alternatives, although they are probably risky for the farmer in those regions where rainfall is low and erratic. Increasing seed density is a strategy to secure a minimum seedling number while reaching full ground cover earlier in the season.

High yields were observed for long growing seasons and warm environments, as in Meknès. This should be attributed to the exponential increase in the rate of mineralization from the humus with soil temperature combined with optimal water regime in the $0-35 \mathrm{~cm}$ of soil. Frequent re-watering of the shallow layers occurred in Meknès conditions when the automatic irrigation procedure was triggered. More generally, the amount of $\mathrm{N}$ mineralization should be evaluated under hot conditions and frequent watering of the mineralization layer.

In this scenario analysis, the 3 environments differed only by climatic conditions (radiation, temperature and precipitation: amount and distribution). The initial values of water and nitrogen in the soil did not change from one year to the next: the effect of the cropping system was ignored although important variations are expected in soil water recharge under rainfed conditions as related to previous crops and actual climatic sequences [3, 22]. Aboudrare et al. [1] simulated wheat-sunflower to account for the variation in initial soil water for sunflower. In the same way, it is well known that the initial nitrogen profile and total available mineral nitrogen may change significantly with the nature and the management of the previous crop.

This simulation exercise was a simplification of the way technical operations are decided by a farmer. Here, we used fixed values of the sowing date and dates of $\mathrm{N}$ fertilization whatever the weather conditions. In water-limited areas, the sowing date depends strictly on fall rainfall. Fertilizer is often buried at sowing to limit the risk of inefficacy of nitrogen top dressings. In spring, the nitrogen amount and timing are governed by rainfall and temperature. A simple decision rule was used to trigger automatic irrigation in relation to the plant water-stress index, which is not an indicator accessible to the farmer. Bergez et al. [5] developed a model where irrigation scheduling was based on the activation of decision rules (if [value of indicator] ... then [action]) in order to realistically represent the decision process of the farmer. Very few models have included a rule-based management module. It is now a challenge for modelers to represent the indicators used by the farmers to decide on applications in order to produce sound and transferable decision rules for any given water limitation scenario.

Important aspects of crop management acting on crop water use and WUE were not evaluated in this study [17, 18]. Applications of $\mathrm{N}$ fertilizer, improved soil tillage and better weed control may increase water transpired as well. Application of mulches could reduce evaporation from the soil surface. Further studies with STICS could evaluate the impacts of N fertilization and mulching on water balance as the effects of these techniques are already included in the model.

Scope for improving TE is limited although genotypic differences exist. Current crop models need to be improved to represent explicitly genotypic differences with some realism [7, 41]. From now on, several cultivar traits which may improve GY in water-limited environments $[29,41]$ could be evaluated with the STICS model (e.g. rooting depth and density, early vigor, assimilate remobilization, threshold for stomatal closure, etc.) in order to identify ideotypes for specific soil-weathermanagement conditions. 


\section{CONCLUSIONS}

The year-to-year variation in total rainfall and its monthly distribution characterizing low rainfall areas generate a wide diversity of scenarios which justified the use of a model instead of experimental determination. This study proved the ability of the STICS model to represent realistically complex interactions between soil, plant, weather and management. The simulation exercise, carried out with the WinStics software, emphasized the need of user-friendly simulation environments as soon as the exploration of wide ranges of soil, weather and management options are required. This is actually a condition to disseminate crop simulation models among agricultural advisers and managers of natural resources.

Acknowledgement: I am grateful to N. Brisson (INRA Avignon) and A. Aboudrare (ENA Meknès) for providing long-term sequences of climatic data.

\section{REFERENCES}

[1] Aboudrare A., Bouaziz A., Debaeke P., Recherche de stratégies de conduite du tournesol dans les conditions pluviales de la région de Meknès (Maroc). II. Simulations à l'aide du modèle EPIC-Phase, Sécheresse 11 (2000) 19-27.

[2] Aboudrare A., Bouaziz A., Debaeke P., Utilisation par le tournesol de l'eau stockée au semis en climat méditerranéen semi-aride, Proceedings 15th International Conference on Sunflower, ISA, Toulouse (France), Vol. I, Sect. C, 2000, pp. 115-120.

[3] Affholder F., Empirically modelling the interaction between intensification and climatic risk in semiarid regions, Field Crops Res. 52 (1997) 79-93.

[4] Anderson W.K., Plant populations for triticale in a Mediterranean environment, Field Crops Res. 8 (1984) 281-295.

[5] Bergez J.E., Debaeke P., Deumier J.M., Lacroix B., Leenhardt D., Leroy P., Wallach D., MODERATO: an object-oriented decision tool for designing maize irrigation schedules, Ecol. Model. 137 (2001) 43-60.

[6] Blum A., Selection for sustained production in water-deficit environments, in: International Crop Science I, CSSA, Madison, WI, USA, 1993, pp. 343-346.

[7] Boote K.J., Kropff M.J., Bindraban P.S., Physiology and modelling of traits in crop plants: implications for genetic improvement, Agric. Syst. 70 (2001) 395-420.

[8] Brisson N., Perrier A., A semi-empirical model of bare soil evaporation for crop simulation models, Water Resour. Res. 27 (1991) 719-727.

[9] Brisson N., Mary B., STICS, version 4.0, Notice Concepts et Formalismes, INRA Avignon, Mai 1999, 59 p.

[10] Brisson N., Seguin B., Bertuzzi P., Agrometeorological soil water balance for crop simulation models, Agric. For. Meteorol. 59 (1992) 267-287.

[11] Brisson N., Mary B., Ripoche D., Jeuffroy M.H., Ruget F., Nicoullaud B., Gate P., Devienne-Barret F., Antonioletti R., Dürr C., Richard G., Beaudoin N., Recous S., Tayot X., Plénet D., Cellier P., Machet J.M., Meynard J.M., Delécolle R., STICS: a generic model for the simulation of crops and their water and nitrogen balances. I Theory and parameterization applied to wheat and corn, Agronomie 18 (1998) 311-346.

[12] Brisson N., Ruget F., Gate P., Lorgeou J., Nicoullaud B., Tayot X., Plénet D., Jeuffroy M.H., Bouthier A., Ripoche D., Mary B., Justes E., STICS: a generic model for the simulation of crops and their water and nitrogen balances. II. Evaluating according to experimental data, Agronomie 22 (2002) 69-92.
[13] Brisson N., Gary C., Justes E., Roche R., Mary B., Ripoche D., Zimmer D., Sierra J., Bertuzzi P., Burger P., Bussière F., Cabidoche Y.M., Cellier P., Debaeke P., Gaudillère J.P., Maraux F., Seguin B., Sinoquet H., An overview of the crop model STICS, Eur. J. Agron. 18 (2003) 309-332.

[14] Cabelguenne M., Jones C.A., Williams J.R., Strategies for limited irrigations of maize in Southwestern France - A modeling approach, Trans. ASAE 38 (1995) 507-511.

[15] Cabelguenne M., Debaeke P., Bouniols A., EPICphase, a version of the EPIC model simulating the effects of water and nitrogen stress on biomass and yield, taking account of developmental stages: validation on maize, sunflower, sorghum, soya and winter wheat, Agric. Syst. 60 (1999) 175-196.

[16] Chapman S.C., Cooper M., Hammer G.L., Using crop simulation to generate genotype by environment interaction effects for sorghum in water-limited environments, Aust. J. Agric. Res. 53 (2002) 379-389.

[17] Connor D.J., Loomis R.S., Strategies and tactics for water-limited agriculture in low rainfall Mediterranean climates, in: Proceedings International Symposium on Improvement and Management of Winter Cereals under Temperature, Drought and Salinity Stresses, INIA, Cordoba, Spain, 1991, pp. 441-465.

[18] Cooper P.J.M., Gregory P.J., Tully D., Harris H.C., Loomis R.S., Improving water use efficiency of annual crops in the rainfed farming systems of West Asia and North Africa, Expl. Agric. 23 (1987) 113-158.

[19] Debaeke P., Wheat response to supplementary irrigation in southwestern France: II. A frequential approach using a simulation model, Agr. Med. 125 (1995) 64-78.

[20] Debaeke P., Supplemental Irrigation, in: Encyclopedia of Water Science, Stewart B.A., Howell T. (Eds.), Marcel Dekker, Inc., New York, 2003, in press.

[21] Debaeke P., Crop management adaptation to water-limited environments, Proceedings 7th ESA Congress, Villalobos F.J., Testi L. (Eds.), Cordoba, Spain, 2002, pp. 33-44.

[22] Debaeke P., Cabelguenne M., Influence of previous crop on available water for a subsequent winter wheat on a deep silty clay soil, Proceedings 3rd ESA Congress, Padova, Italy, 1994, pp. 682-683.

[23] Fereres E., Orgaz F., Villalobos F.J., Water use efficiency in sustainable agricultural systems, in: International Crop Science I, CSSA, Madison, WI, USA, 1993, pp. 83-89.

[24] Fischer R.A., Kohn G.D., The relationship of grain yield to vegetative growth and post-flowering leaf area in the wheat crop under conditions of limited soil moisture, Aust. J. Agric. Res. 17 (1966) 281-295.

[25] Gate P., Ecophysiologie du blé : de la plante à la culture, ITCF \& Lavoisier, Paris, 1995, 429 p.

[26] Hanks R.J., Sorensen R.B., Harvest index of spring wheat as influenced by water stress, in: Day W., Atkin R.K. (Eds.), Wheat Growth and Modelling, NATO-ASI Series, Plenum Press, NewYork, 1985, pp. 205-209.

[27] Loss S.P., Siddique K.H.M., Morphological and physiological traits associated with wheat yield increases in Mediterranean environments, Adv. Agron. 52 (1994) 229-276.

[28] Ludlow M.M., Strategies of response to water stress, in: Kreeb K.H., Ritcher H., Hinckley T.M. (Eds.), Structural and Functional Responses to Environmental Stresses, SPB Academic Publishing, Gravenhage, The Netherlands, 1989, pp. 269-281.

[29] Ludlow M.M., Muchow R.C., A critical evaluation of traits for improving crop yields in water-limited environments, Adv. Agron. 43 (1990) 107-153.

[30] McCown R.L., Hammer G.L., Hargreaves J.N.G., Holzworth D.P., Freebairn D.M., APSIM: a novel software system for model development, model testing, and simulation in agricultural system research, Agric. Syst. 50 (1996) 255-271.

[31] Meinke H., Hammer G.L., Chapman S.C., A sunflower simulation model. II. Simulating production risks in a variable sub-tropical environment, Agron. J. 85 (1993) 735-742. 
[32] Muchow R.C., Hammer G.L, Vanderlip R.L., Assessing climatic risk to sorghum production in water-limited subtropical environments. II. Effects of planting date, soil water at planting, and cultivar phenology, Field Crops Res. 36 (1994) 235-246.

[33] Passioura J.B., Grain yield, harvest index and water use of wheat, J. Aust. Inst. Agric. Sci. 43 (1977) 117-120.

[34] Rosenthal W.D., Gerik T.J., Application of a crop model to evaluate cultural practices and optimize dryland grain sorghum yield, J. Prod. Agric. 3 (1990) 124-131.

[35] Sadras V.O., Hall A.J., Patterns of water availability for sunflower crops in semi-arid Central Argentina. A simulation-based evaluation of their interactions with cropping strategies and cultivar traits, Agric. Syst. 31 (1989) 221-238.

[36] Singels A., Evaluating wheat planting strategies using a growth model, Agric. Syst. 38 (1992) 175-184.
[37] Sivakumar M.V.K., Glinni A.F., Applications of crop growth models in the semiarid regions, in: Ahuha L.R., Ma L., Howell T.A. (Eds.), Agricultural System Models in Field Research and Technology transfer, Lewis Publishers, 2002, pp. 178-205.

[38] Soltani A., Galeshi S., Importance of rapid canopy closure for wheat production in a temperate sub-humid environment: experimentation and simulation, Field Crops Res. 77 (2002) 17-30.

[39] Stapper M., Harris H.C., Assessing the productivity of wheat genotypes in an Mediterranean climate using a crop-simulation model, Field Crops Res. 20 (1989) 129-152.

[40] Stockle C.O., Martin S., Campbell G.S., CropSyst, a cropping systems model: water/nitrogen budgets and crop yield, Agric. Syst. 46 (1994) 335-359.

[41] Sinclair T.R., Muchow R.C., System analysis of plant traits to increase grain yield on limited water supplies, Agron. J. 93 (2001) 263-270. 